\title{
Charnley-Kerboull total hip arthroplasty combining zirconia on polyethylene. A minimum eight-year follow-up prospective study
}

\author{
Jean Langlois • Samer El Hage • Faouzi Madi • Jean-Pierre Courpied • \\ Marcel Kerboull • Moussa Hamadouche
}

Received: 8 January 2013 / Accepted: 10 January 2013 /Published online: 31 January 2013

(C) Springer-Verlag Berlin Heidelberg 2013

\begin{abstract}
Purpose Zirconia was introduced in the 1980s for total hip arthroplasty (THA) with the expectation of lower polyethylene wear. The purpose of this prospective study was to evaluate the results of a continuous series of total hip arthroplasties combining a zirconia head with polyethylene socket at a minimum eight-year follow-up.

Methods We performed an open prospective clinical trial in 1997. Our study involved 51 consecutive patients (55 hips) with a mean age of $52.5 \pm 12$ years (range, $25-76$ years). All patients had a Charnley-Kerboull all-cemented hip replacement. A 22-mm stabilised yttrium tetragonal polycrystalline zirconia head (Y-TZP) was used in association with moderately cross-linked and annealed polyethylene. Clinical and radiological outcomes were assessed yearly. A survival analysis was performed using revision for any reason as the end-point.

Results At a minimum eight-year follow-up, 12 patients (13 hips) were lost to follow-up (mean 26.8 months), two patients (two hips) had died, and six patients (six hips) were revised. The remaining 31 patients (34 hips) were alive and had not been revised on either the femoral or acetabular side at a mean follow-up of 117.1 months (range, 96150 months). Mean functional score at last follow-up was 17.7. Mean linear head penetration was $0.23 \mathrm{~mm} /$ year. More than $90 \%$ of the remaining hips had signs of periprosthetic osteolysis. Five stems were loosened. The survival at eight years was $87.3 \%$ (95\% IC: 76.7-97.8).
\end{abstract}

J. Langlois $\cdot$ S. El Hage $\cdot$ F. Madi $\cdot$ J.-P. Courpied $\cdot$ M. Kerboull $\cdot$

M. Hamadouche $(\square)$

Clinical Orthopaedic Research Centre, Department

of Reconstructive and Orthopaedic Surgery, Université Paris

Descartes, Hôpital Cochin (AP-HP), Paris, France

e-mail: moussah@club-internet.fr

J. Langlois

e-mail: jeangast@gmail.com
Conclusion This study confirms earlier short-terms results, and demonstrates that zirconia should no longer be used in THA.

\section{Introduction}

Polyethylene (PE) wear and polyethylene particles-induced periprosthetic osteolysis currently remain the major limitations to the long-term performance of total hip arthroplasty (THA) [1]. To reduce polyethylene wear, alumina ceramic femoral heads were introduced in the early 1970's [2]. However, the relatively brittle nature of alumina was responsible for a high rate of fracture, ranging from 0.02 to $0.14 \%$ [3]. Improvements in the manufacturing process, with a low grain size and grain distribution, dramatically decreased the risk of crack propagation and rate of fracture. Despite these improvements, the use of $22.2 \mathrm{~mm}$ diameter alumina ceramic femoral heads is not recommended.

Zirconia ceramic femoral heads were introduced in orthopaedics in 1985 because of the high strength and fracture toughness of the material, which would reduce the risk for fracture [4]. Moreover, the physical properties of the material were improved with the introduction of the hot isostatic pressure (HIP) process [5]. These mechanical properties allowed the development of $22.2 \mathrm{~mm}$ diameter femoral heads. Also, zirconia has a high scratch resistance. A number of in-vitro studies have reported a reduced rate of polyethylene wear articulating against zirconia [5-7]. Despite such promising in vitro data, so far the clinical evidence has been limited. Indeed, Allain et al. have reported poor survivorship of zirconia against PE in THA, with $14 \%$ of aseptic loosening at a mean 5.8 year follow-up [8]. These results were confirmed by Hernigou et al. [9], Nakahara et al. [10], Yoshitomi et al. [11], and more recently Kadar et al. 
[12]. This phenomenon was related to an intensive in vivo phase transformation in the crystal structure of retrieved head, ranging from $1 \%$ to $30 \%$ [13]. This phenomenon would lead to increased surface roughness of the zirconia heads $[13,14]$, and volumetric expansion of approximately three to four percent [13].

At the authors' institution, Charnley-Kerboull prostheses have been used since 1972, with a higher than $80 \%$ survival rate of the prosthesis at 20 years [15]. To investigate the alleged decreased wear of polyethylene articulating with zirconia, an open prospective clinical trial was started in 1997. While there is some evidence suggesting that zirconia may become unstable in vivo, this material currently continues to be widely used in THA. The aim of this study was to report on a short series of Charnley-Kerboull total hip arthroplasties combining zirconia femoral heads on polyethylene with a minimum eight-year follow-up.

\section{Materials and methods}

Between January 1997 and June 1999, 51 patients had 55 total hip replacements performed by the senior author (M.K.). There were 30 females (33 hips) and 21 males (22 hips) in this series. All patients had given informed consent and the study was institutional review board (IRB) approved. The average age of the patients at the time of the index arthroplasty was $52.5 \pm 12$ years (range, 25-76 years). The mean body mass index of the series was $23.9 \pm 3.4 \mathrm{~kg} / \mathrm{m}^{2}$ (range, 18 $33.5 \mathrm{~kg} / \mathrm{m}^{2}$ ). The right hip was operated on in 31 patients and the left in 18, whereas three patients had bilateral replacement. Patient's demographic data and initial diagnoses are summarised in Table 1. Eleven of the 55 hips had had a total hip replacement before the index arthroplasty. Total replacement was performed through a lateral approach with a trochanteric osteotomy in all cases.

A zirconia on polyethylene combination was used in all patients, and implants were of Charnley-Kerboull design
(Fig. 1). The femoral stem was made of highly polished stainless steel (Orthinox ${ }^{\circledR}$, Legend ${ }^{\circledR}$, Benoist-Girard, Stryker Howmedica, Herouville Saint-Clair, France). The socket was made of moderately cross-linked polyethylene (Duration ${ }^{\circledR}$, Benoist-Girard). Cross-linking was performed through sterilisation of GUR 415 ultra-high molecular weight polyethylene with $3.0 \mathrm{Mrad}$ of gamma irradiation in an atmosphere of nitrogen and then subjecting the packaged components to an annealing cycle to promote further cross-linking via a radical quenching mechanism. Both components were fixed according to a second-generation technique using CMW type 1 bone cement (Depuy 1 Bone cement, Exeter, Devon, England). This cement contained barium sulphate as a radio-opacifying agent, and was zirconium oxide free.

The $22.2 \mathrm{~mm}$ femoral head was made of yttria-stabilised tetragonal zirconia polycrystal ceramic (Y-TZP), processed according to the hot isostatic pressure procedure (Prozyr ${ }^{\circledR}$, Norton Demarquest, Evreux, France). The main characteristics of the material as indicated by the manufacturer comparatively to International Standards Organisation (ISO 13356) are summarised in Table 2. The zirconia femoral head was secured to the femoral stem through a Morse taper that had an angle of $11^{\circ} 25$ in 27 hips and $5^{\circ} 40$ in the remaining 28 hips.

Postoperative treatment included anticoagulation therapy, systemic antibiotics and non-steroidal anti-inflammatory drugs (ketoprofen, 100 milligrams per day) to prevent heterotopic ossification. Immediate postoperative passive motion exercises of the replaced joint were undertaken. Passive motion exercises were therapist assisted, and were pursued until active motion of the hip was possible. Patients were free to walk with two supports after three days. Full weight bearing was usually allowed after six weeks.

Clinical and radiological evaluations were performed at six weeks, three months, six months, one year, and then every one or two years thereafter. The operating surgeon evaluated all patients. Hip functional results were rated according to the d'Aubigné grading system [16].
Table 1 Patients' demographic data

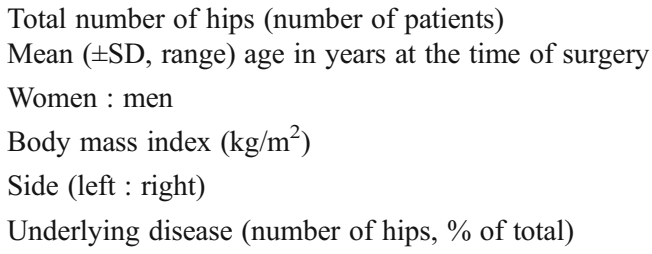

Total number of hips (number of patients)

Mean $( \pm \mathrm{SD}$, range) age in years at the time of surgery

Women : men

Body mass index $\left(\mathrm{kg} / \mathrm{m}^{2}\right)$

Side (left : right)

Underlying disease (number of hips, \% of total)

$\begin{array}{lr}55(51) & \\ 52.5 \pm 12.5(25-76) & \\ 30: 21 & \\ 23.9 \pm 3.4(18-35) & 27(49.1) \\ 21: 34 & 16(29.1) \\ \text { primary osteoarthritis } & 4(7.3) \\ \text { congenital dysplasia } & 3(5.5) \\ \text { post-traumatic arthritis } & 2(3.6) \\ \text { avascular necrosis } & 2(3.6) \\ \text { rheumatoid arthritis } & 1(1.8) \\ \text { ankylosing spondylitis } & \\ \text { villonodular synovitis } & \end{array}$




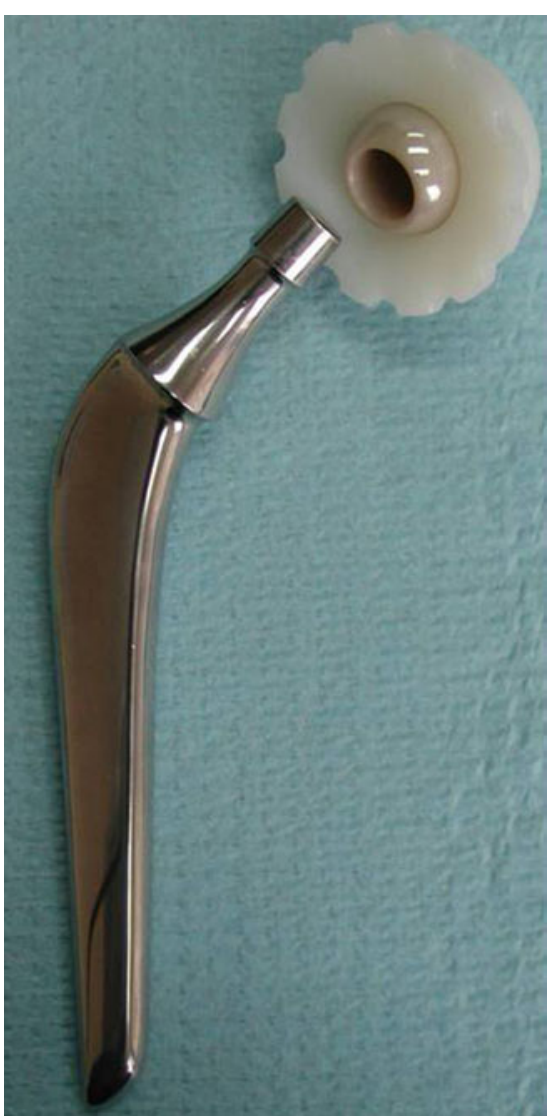

Fig. 1 Charnley-Kerboull total hip arthroplasty combining zirconia on polyethylene

Radiographic analysis was performed on serial anteroposterior radiographs of the pelvis by the same independent observer. The position of the socket relative to the horizontal and vertical tear-drop line, the inclination angle of the cup and the presence and evolution of radiolucent lines according to DeLee and Charnley [17] were evaluated on the pelvic side. Loosening of the socket was defined as a cup migration exceeding three millimetres, an angular rotation exceeding 3 degrees, or a continuous radiolucent line wider than two millimetres. Linear wear of the acetabular component was determined by measuring the change in the shortest distance between the centre of the femoral head and the periphery of the acetabular component as seen on the immediate postoperative radiograph compared with that seen on those made at the latest follow-up evaluation, as described by Livermore et al. [18]. Measurements were made with a caliper that had an accuracy of $0.5 \mathrm{~mm}$. Correction for magnification was performed using the data from the radius of the femoral head. On the femoral side, parameters investigated were the evolution of radiolucent lines in the seven zones of the femur [19], calcar resorption, and subsidence of the stem. Loosening of the stem was defined as a migration exceeding three millimetres or a continuous radiolucent line wider than two millimetres.

Cystic or scalloped lesions greater than two millimetres in diameter around the prosthetic components that were not present on the immediate postoperative radiograph were defined as osteolysis [20]. A survivorship analysis according to the actuarial method [21] was carried out on the entire series, using revision for any reason at the time of follow-up as endpoint. The survival curve was derived from the cumulative survival rate as calculated from the actuarial life table. The standard error, given as percentage, and the $95 \%$ confidence intervals (CIs), were calculated from the data in the life table. Statistical analysis was performed using nonparametric tests. Significance was defined as a $p$ value of less than 0.05 (StatView 5.0 Statistical Software, SAS Institute Inc., USA).

\section{Results}

At a minimum eight-year follow-up, 12 patients (13 hips) were lost to follow-up (mean 26.8 months), two patients (two hips) had died, and six patients (six hips) were revised. The remaining 31 patients ( 34 hips) were alive and had not been revised on either the femoral or acetabular side at a mean follow-up of 117.1 months (range 96-150 months).
Table 2 Physical and chemical properties of zirconia ceramics

\begin{tabular}{lll}
\hline Property & ISO 13356 & Prozyr $($ Norton Demarquest) \\
\hline $\mathrm{ZrO}_{2}(\%)$ & $>94.2$ & $>$ \\
$\mathrm{Y}_{2} \mathrm{O}_{3}(\%)$ & $5.1 \pm 0.3$ & $5.1 \pm 0.3$ \\
Density $\left(\mathrm{g} / \mathrm{cm}^{3}\right)$ & $>6.00$ & $>6.08$ \\
Mean grain size $(\mu \mathrm{m})$ & $<0.5$ & $<0.5$ \\
Surface finish $(\mathrm{Ra}, \mu \mathrm{m})$ & - & $>600$ \\
Compressive strength $(\mathrm{MPa})$ & 2000 & - \\
Young's modulus $(\mathrm{GPa})$ & 210 & - \\
Bending strength $(\mathrm{Mpa})$ & $>900$ & $>1500$ \\
Biaxial strength & - & $>600$ \\
Fracture toughness Mpa m & - & $8-\mathrm{Oct}$ \\
Monoclinic phase & & \\
\hline
\end{tabular}


Six patients (six hips in five women and one man) were revised after a mean follow-up of 85.7 months (range, 43143). The mean age of these patients at the time of the index arthroplasty was $50.7 \pm 8.0$ years (41.2 to 63 ). All revision procedures were performed on both the acetabular and the femoral side. Revisions were done because of socket wear and loosening associated with periacetabular and extensive femoral osteolysis.

The mean Merle d'Aubigné functional hip score increased from $12.1 \pm 2.7$ preoperatively to $17.9 \pm 0.1$ at last follow-up (Wilcoxon rank test, $p<0.001$ ). No patient had infection, no prosthesis dislocation occurred, and no femoral head fracture was recorded. The mean abduction angle of the socket was $41.9 \pm 5.7^{\circ}$ (range, $29-52^{\circ}$ ). At the latest follow-up, the mean linear penetration rate according to Livermore technique was $0.23 \mathrm{~mm} /$ year (range, 0.15 0.48). Osteolysis was observed in 31 of the 34 remaining hips $(91.2 \%)$. We diagnosed 24 cases of isolated endosteal defect in the calcar (Zone VII from Gruen's classification), seven cases of extended femoral osteolysis, and seven cases of acetabular osteolysis. Nineteen cases of lytic lesions in Zone VII occurred before the end of the second year. Radiographic stem loosening was recorded in five cases (Figs. $2 \& 3$ ), according to the criteria used in this study. We were unable to identify any factor predictive of these osteolytic lesions, testing preoperative parameters such as

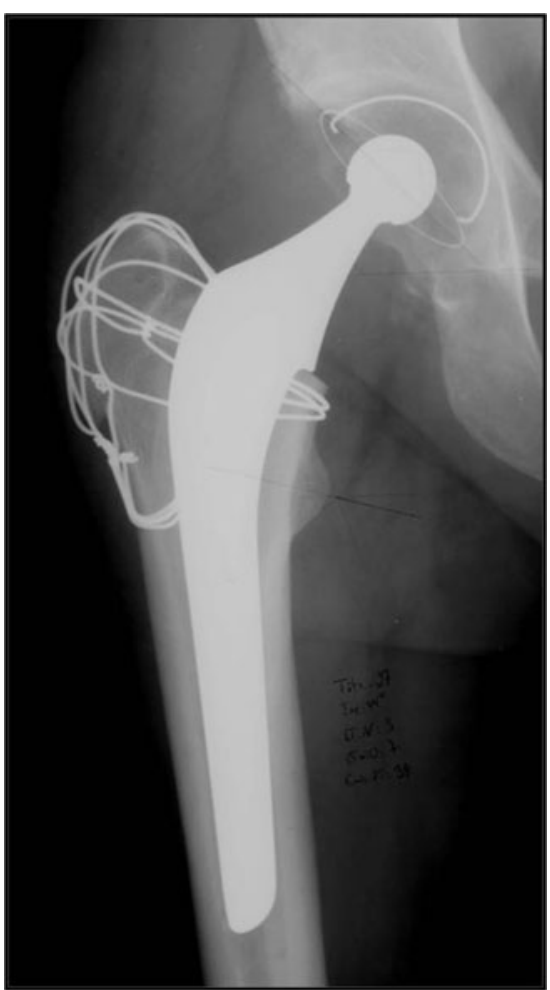

Fig. 2 Postoperative radiograph of a 67-year-old male who underwent total hip arthroplasty for primary osteoarthritis body mass index (BMI), age, gender or angulation of Morse taper.

Using revision for any reason as the end-point, the survival rate at eight years was $87.3 \%$ (95\% IC: 76.7-97.8). (Table 3 and Fig. 4).

\section{Discussion}

Surgical grade zirconia ceramic was introduced in orthopaedics in 1985. The metastable nature of zirconia required the use of yttria to enable stability of the material in its tetragonal allotropic phase. The biocompatibility and the low magnitude of inflammatory response induced by zirconia particles have been demonstrated in vitro [22]. Most of the reported in vitro studies demonstrated lower rates of polyethylene wear articulating with zirconia when compared to metal $[4,5]$, comparable to those obtained with alumina on polyethylene [6].

Clinical results published in the literature are less favourable. Allain et al. [8] reported one of the first consecutive series of 100 total hip arthroplasties using $28 \mathrm{~mm}$ zirconia femoral heads articulating with polyethylene. At a mean

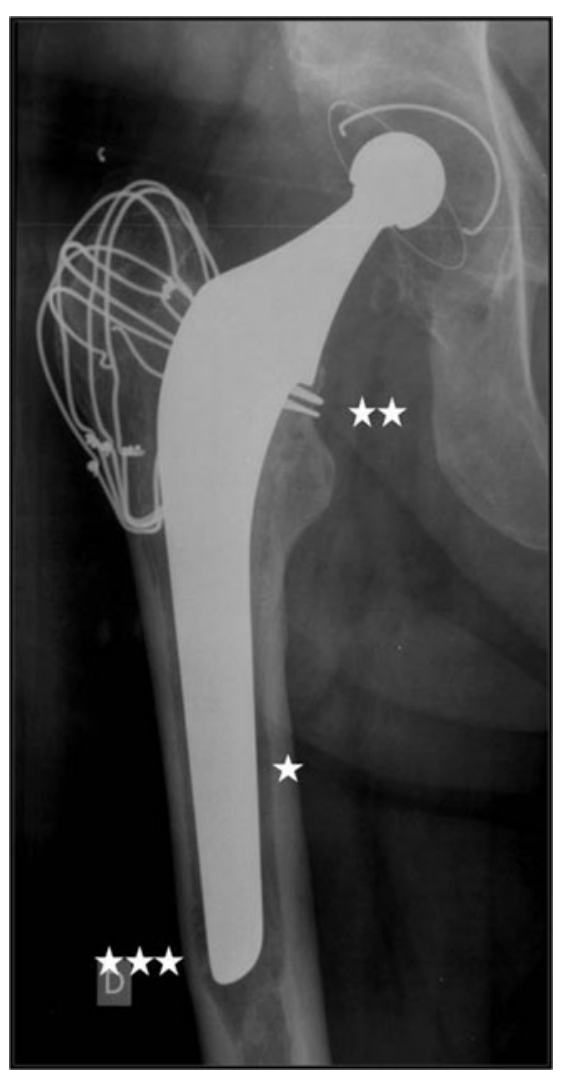

Fig. 3 Radiograph made at 121-month follow-up, showing continuous radiolucency at bone cement interface $(*)$, calcar resorption $(* *)$, subsidence $(* *)$ and distal lateral shift $(* * *)$ of the stem; the patient suffered from thigh pain 
Table 3 Life table, with revision for any reason as the endpoint

\begin{tabular}{|c|c|c|c|}
\hline $\begin{array}{l}\text { Time from the } \\
\text { surgery (year) }\end{array}$ & $\begin{array}{l}\text { Survival } \\
\text { rate }(\%)\end{array}$ & $\begin{array}{l}\text { Lower } 95 \% \\
\text { confidence limit }\end{array}$ & $\begin{array}{l}\text { Upper } 95 \% \\
\text { confidence limi }\end{array}$ \\
\hline 0 & 100.00 & 100.00 & 100.00 \\
\hline 1 & 100.00 & 100.00 & 100.00 \\
\hline 1 & 100.00 & 100.00 & 100.00 \\
\hline 2 & 100.00 & 100.00 & 100.00 \\
\hline 2 & 100.00 & 100.00 & 100.00 \\
\hline 3 & 100.00 & 100.00 & 100.00 \\
\hline 3 & 100.00 & 100.00 & 100.00 \\
\hline 4 & 100.00 & 100.00 & 100.00 \\
\hline 4 & 98.02 & 93.54 & 100.00 \\
\hline 5 & 97.80 & 93.54 & 100.00 \\
\hline 5 & 97.80 & 93.54 & 100.00 \\
\hline 6 & 97.80 & 93.54 & 100.00 \\
\hline 6 & 95.33 & 88.99 & 100.00 \\
\hline 7 & 95.33 & 88.99 & 100.00 \\
\hline 7 & 90.31 & 81.26 & 99.36 \\
\hline 8 & 90.31 & 81.26 & 99.36 \\
\hline 8 & 90.31 & 81.26 & 99.36 \\
\hline 9 & 90.31 & 81.26 & 99.36 \\
\hline 9 & 87.25 & 76.70 & 97.79 \\
\hline 10 & 87.25 & 76.70 & 97.79 \\
\hline 10 & 87.25 & 76.70 & 97.79 \\
\hline 11 & 87.25 & 76.70 & 97.79 \\
\hline 11 & 87.25 & 76.70 & 97.79 \\
\hline 12 & 87.25 & 76.70 & 97.79 \\
\hline
\end{tabular}

follow-up of 5.8 years, $13 \%$ of acetabular loosening and $47.5 \%$ radiolucent lines at the cement bone interface occurred on the acetabular side, whereas on the femoral side $2.5 \%$ of femoral loosening and $21.7 \%$ of radiolucent lines at the cement bone interface were observed. Moreover, a $20 \%$ rate of calcar lysis was seen. The survival rate at eight years was $63 \%$. Histological analysis revealed zirconia particles. The authors postulated that zirconia particles of low purity occurred from cement opacifier, rather than from the articulating surface. Haraguchi et al. [23] reported on two cases of phase transformation of retrieved zirconia femoral heads. The monoclinic content of the zirconia ceramics rose from $1 \%$ to about $30 \%$ on the surface of the heads. Surface electron microscopy revealed numerous craters, indicating extraction of the zirconia ceramics at the surface. Surface roughness increased from an initial value of $0.006 \mu \mathrm{m}$ up to $0.12 \mu \mathrm{m}$. Nakahara et al. [10] identified in a prospective controlled trial with a mean follow-up of 6.7 years, no difference in terms of penetration rate or osteolysis between 26 millimetre zirconia and cobalt chromium heads against highly cross-linked polyethylene. Yoshitomi et al. [11] reported in a recent meta-analysis the results of seven well-designed studies evaluating the combination zirconia against polyethylene. These involved 769 hips of 586 patients and a mean follow-up of 89.2 months (ranging from 60 to 155 months). The consolidated revision rate of zirconia-polyethylene THA at 89.2 months was higher than that of nonzirconia-polyethylene THA by five percent (risk difference, 0.05; confidence interval, 0.020.08). Furthermore, subgroup analysis suggested different survival rates between the different types of zirconia head. Finally, Kadar et al. [12] published results of comparative head material survival rates based on the Norwegian Arthroplasty Register. With any revision as the end point, at 12 years, the survival with zirconia heads $(74.8 \%)$ was inferior to the survival with cobalt-chromium heads $(88.1 \%)$ ( $p=0.002$, Cox analysis, adjusted for age, sex and diagnosis).

The absence of correlation between hip simulator studies and clinical results could be interpreted in light of Lu et al.'s findings [24]. These authors have shown that major frictional heating was observed in vitro when testing zirconia against polyethylene. This phenomenon was responsible for proteins lubricant precipitation. The resultant protein layer between the femoral head and polyethylene socket
Fig. 4 Survival curve, with revision for any reason as the endpoint

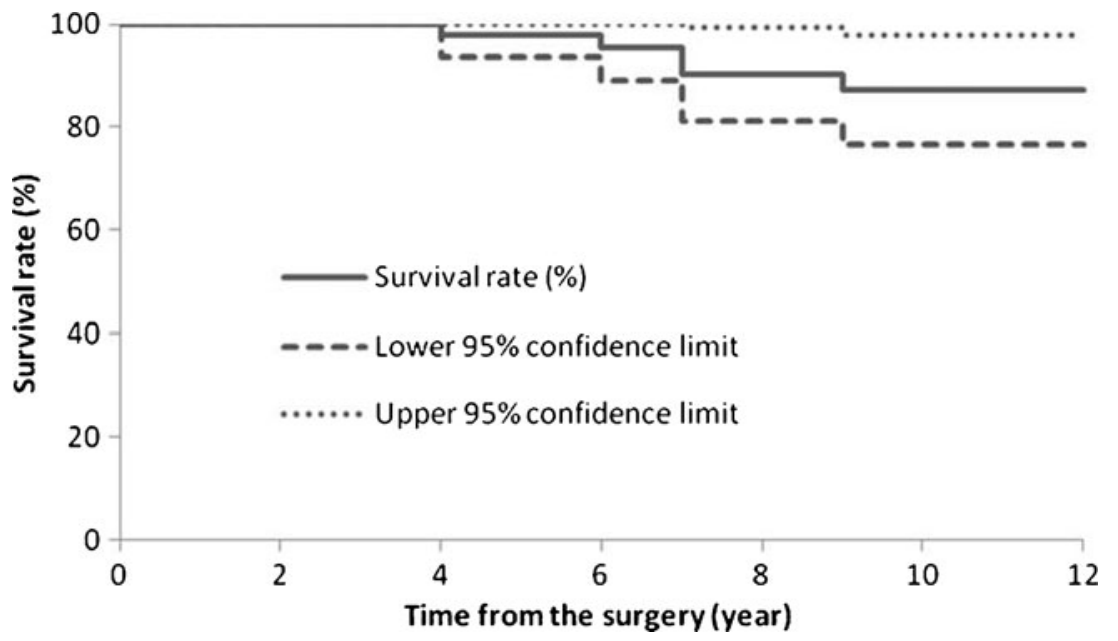


could protect the bearing surfaces from wear. The maximum temperatures reached in vivo are probably much lower than those observed in the hip simulator, as patients do not walk so fast for such a long time. In this respect, hip simulators probably underestimate polyethylene wear.

Some limitations in our prospective cohort study should be considered. First, no retrieval analysis was investigated (neither surface roughness, nor phase analysis). Second, we also regret that almost $26 \%$ of the initial series was lost to follow-up. Third, we did not design a control group of patients, using cobalt-chromium femoral heads. However, this cohort could be compared with another one from our institution [15]. Kerboull et al. retrospectively evaluated 287 THA from 222 young patients (mean age of $40.1 \pm 8$ years, range from 15.5 to 50 ) with an association of cobaltchromium head against conventional polyethylene. The survivorship analysis with revision of either component for any reason as the end point yielded a $85.4 \%$ cumulative survival rate at 20 years ( $95 \%$ IC : $78.4 \%-92.4 \%$ ). Zirconia heads in our study revealed almost the same rate, but at only eight years.

In this clinical study, although zirconia was used under optimal conditions, including a single experienced surgeon, hot isostatic pressure process, a zirconium free bone cement, a $22-\mathrm{mm}$ head and a moderately cross-linked and annealed polyethylene, we observed at two to four-year follow-up a moderate osteolysis of the proximal femur in one third of the hips [25]. This phenomenon was interpreted as the first step of major wear that would increase with longer-term followup. At that time, we decided to suspend the implantation of zirconia femoral heads until long-term follow-up results were obtained. This current midterm study, supported by evidence-based literature [11, 12], confirms that zirconia offers no advantage over a cobalt-chromium head in decreasing in vivo polyethylene wear. Moreover, it appears as a nonviable tribological option, even when using a $22 \mathrm{~mm}$ head and a partially cross-linked and annealed polyethylene. This study emphasises once again that in vitro results of a material should be projected with extreme caution to its in vivo behavior.

\section{References}

1. Goodman S, Huie P, Song Y et al (1997) Loosening and osteolysis of cemented joint arthroplasties. A biologic spectrum. Clin Orthop Relat Res 337:149-163

2. Hannouche D, Zaoui A, Zadegan F, Sedel L, Nizard R (2011) Thirty years of experience with alumina-on-alumina bearings in total hip arthroplasty. Int Orthop 35(2):207-213

3. Fritsch E, Gleitz M (1996) Ceramic femoral head fractures in total hip arthroplasty. Clin Orthop Relat Res 328:129-136
4. Piconi C, Burger W, Richter HG et al (1998) Y-TZP ceramics for artificial joint replacements. Biomaterials 19:1489-1494

5. Cales B (2000) Zirconia as a sliding material: histologic, laboratory, and clinical data. Clin Orthop Relat Res 379:94-112

6. Derbyshire B, Fisher J, Dowson D, Hardaker C, Brummitt K (1994) Comparative study of the wear of UHMWPE with zirconia ceramic and stainless steel femoral heads in artificial hip joints. Med Eng Phys 16:229-236

7. Goldsmith AA, Dowson D (1999) A multi-station hip joint simulator study of the performance of $22 \mathrm{~mm}$ diameter zirconia-ultrahigh molecular weight polyethylene total replacement hip joints. Proc Inst Mech Eng 213:77-90

8. Allain J, Le Mouel S, Goutallier D, Voisin MC (1999) Poor eightyear survival of cemented zirconia-polyethylene total hip replacements. J Bone Joint Surg Br 81-B:835-842

9. Hernigou P, Bahrami T (2003) Zirconia and alumina ceramics in comparison with stainless-steel heads. Polyethylene wear after a minimum ten-year follow-up. J Bone Joint Surg Br 85(4):504-509

10. Nakahara I, Nakamura N, Nishii T, Miki H, Sakai T, Sugano N (2010) Minimum five-year follow-up wear measurement of longevity highly cross-linked polyethylene cup against cobalt-chromium or zirconia heads. J Arthroplasty 25(8):1182-1187

11. Yoshitomi H, Shikata S, Ito H, Nakayama T, Nakamura T (2009) Manufacturers affect clinical results of THA with zirconia heads: a systematic review. Clin Orthop Relat Res 467(9):2349-2355

12. Kadar T, Dybvik E, Hallan G, Furnes O, Havelin LI (2012) Head material influences survival of a cemented total hip prosthesis in the Norwegian Arthroplasty Register. Clin Orthop Relat Res 470 (11):3007-3013

13. Brown S, Green D, Pezzotti G, Donaldson T, Clarke I (2008) Possible triggers for phase transformation in zirconia hip balls. J Biomed Mater Res B Appl Biomater 85:444-452

14. Piconi C, Maccauro G (1999) Zirconia as a ceramic biomaterial. Biomaterials 20:1-25

15. Kerboull L, Hamadouche M, Courpied JP, Kerboull M (2004) Longterm results of Charnley-Kerboull hip arthroplasty in patients younger than 50 years. Clin Orthop Relat Res 418:112-118

16. Merle d'aubigné R (1970) Cotation chiffree de la fonction de la hanche. Rev Chir Orthop 56:481-486

17. De Lee J, Charnley J (1976) Radiological demarcation of cemented sockets in total hip replacement. Clin Orthop Relat Res 121:20-32

18. Livermore J, Ilstrup D, Morrey B (1990) Effect of femoral head size on wear of the polyethylene acetabular component. J Bone Joint Surg Am 72:518-528

19. Gruen TA, McNeice GM, Amstutz HC (1979) "Modes of failure" of cemented stem-type femoral components: a radiographic analysis of loosening. Clin Orthop Relat Res 141:17-27

20. Maloney WJ, Jasty M, Harris WH, Galante JO, Callaghan JJ (1990) Endosteal erosion in association with stable uncemented femoral components. J Bone Joint Surg Am 72:1025-1034

21. Murray DW, Carr AJ, Bulstrode C (1993) Survival analysis of joint replacements. J Bone Joint Surg Br 75-B:697-704

22. Christel P (1992) Biocompatibility of surgical-grade dense polycrystalline alumina. Clin Orthop Relat Res 282:10-18

23. Haraguchi K, Sugano N, Nishii T, Nishii T, Miki H, Oka K, Yoshikawa H (2001) Phase transformation of a zirconia ceramic head after total hip arthroplasty. J Bone Joint Surg Br 83:996-1000

24. Lu Z, McKellop H, Liao P, Benya P (1999) Potential thermal artifacts in hip joint wear simulators. J Biomed Mater Res 48:458-464

25. Hamadouche M, Madi F, Kerboull L, Courpied JP, Kerboull M (2005) Early femoral osteolysis following Charnley-Kerboull total hip arthroplasty combining a $22-\mathrm{mm}$ zirconia head on polyethylene. Rev Chir Orthop 91(5):439-445 